\title{
Identification and Characterization of "Candidatus Rickettsia Thierseensis", a Novel Spotted Fever Group Rickettsia Species Detected in Austria
}

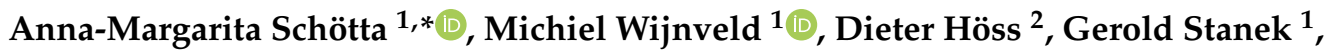 \\ Hannes Stockinger ${ }^{1}$ (D) and Mateusz Markowicz ${ }^{1}$ \\ 1 Institute for Hygiene and Applied Immunology, Center for Pathophysiology, Infectiology and Immunology, \\ Medical University of Vienna, Kinderspitalgasse 15, A-1090 Vienna, Austria; \\ michiel.wijnveld@meduniwien.ac.at (M.W.); gerold.stanek@meduniwien.ac.at (G.S.); \\ hannes.stockinger@meduniwien.ac.at (H.S.); mateusz.markowicz@meduniwien.ac.at (M.M.) \\ 2 Private Medical Office, Vorderthiersee 19, 6335 Thiersee, Austria; hoess.thiersee@a1business.at \\ * Correspondence: anna-margarita.schoetta@meduniwien.ac.at; Tel.: +43-1-40160-33013
}

Received: 17 September 2020; Accepted: 23 October 2020; Published: 28 October 2020 updates

\begin{abstract}
Rickettsia spp. are the second most common pathogens detected in Ixodes ricinus ticks in Austria after Borrelia burgdorferi sensu lato. Species belonging to the spotted fever group (SFG) are the causative agents for tick-borne rickettsiosis across the world. So far, only four SFG Rickettsia spp. were detected in Austria, namely R. helvetica, R. raoultii, R. monacensis and $R$. slovaca. Here, we describe the identification of a new SFG Rickettsia species detected in an I. ricinus tick. Sequencing of various rickettsial genes revealed a nucleotide sequence similarity of $99.6 \%, 98.5 \%, 97.3 \%$ and $98.5 \%$ to the $\mathrm{glt} A$, отр $A$, отр B, and sca 4 genes, respectively, of known and validated species. Additionally, sequencing of the $h$ tr $A$ gene and 23S-5S intergenic spacer region also only showed $99.6 \%$ and $99.2 \%$, respectively, similarity to known species. Therefore, and in accordance with current criteria for Rickettsia species discrimination, we hereby describe a new species of the SFG with putative pathogenic potential. We propose the name "Candidatus Rickettsia thierseensis" based on the village Thiersee in the Austrian province of Tyrol, where the carrying tick was found.
\end{abstract}

Keywords: Austria; spotted fever group Rickettsia; Ixodes ricinus; ticks; Candidatus Rickettsia thierseensis

\section{Introduction}

Rickettsia spp. are obligate intracellular bacteria that can be divided into several groups: (a) the spotted fever group (SFG) is the largest one. It contains strains commonly found in ticks, mites and fleas that can cause spotted fever in humans. (b) The typhus group (TG) comprises R. prowazekii and R. typhi, which are transmitted by lice and fleas and cause typhus in humans. (c) The ancestral group is based on the most outlying Rickettsia spp. which are R. canadensis and R. belli. (d) Lastly, the so-called transitional group has recently been described which includes species previously assigned to the SFG, however, this group is still discussed controversially [1,2]. Some species that were previously not considered pathogenic to humans are nowadays proven pathogens [3]. Thus, surveillance studies investigating the presence of Rickettsia spp. circulating in our environment—especially within arthropods, like ticks that can act as vectors-are of great medical importance.

In Austria, Ixodes ricinus (I. ricinus) is the most abundant vector of zoonotic diseases and, therefore, the most dangerous tick species from a medical point of view. The prevalence of Rickettsia spp. in the Austrian I. ricinus population ranges between $7 \%$ and $50 \%$ depending on the collection site [4]). Thus, besides Borrelia burgdorferi sensu lato, Rickettsia spp. of the SFG species are the most frequent 
pathogens detected in ticks. Until now, the detected SFG rickettsiae in Austria comprise the genospecies R. helvetica, $R$. raoultii, $R$. monacensis and $R$. slovaca [4].

Here, we describe a new SFG Rickettsia sp. which we found in a tick obtained from a healthy human host in Thiersee, a village in the Austrian province of Tyrol. We characterized this species using various genes commonly used for the discrimination of Rickettsia spp. in agreement with gene sequence-based criteria used in tick-borne Rickettsia research [5], as well as by performing a multigenic molecular approach. All assays performed confirm the presence of a new SFG Rickettsia sp.

\section{Materials and Methods}

\subsection{Tick Identification and DNA Extraction}

The unengorged tick was obtained from a healthy person who participated in a study at our institute. The study was approved by the Ethical Committee of the Medical University of Vienna (1064/2015, approval date: 08/06/2015) and of the Medical University of Innsbruck (AN2016-0043-359/4.16, approval date: 09/05/2016). According to the study participant, the tick was removed from the right hand within the first hour of attachment.

Morphological identification was done using a stereomicroscope in combination with an Ixodes spp. identification key. Additionally, molecular identification was performed based on the mitochondrial 16S rRNA gene using primers 16S+1 (5'-CTGCTCAATGATTTTTTAAATTGCTGTGG-3') and 16S-1 (5'-CCGGTCTGAACTAGATCAAGT-3') [6].

DNA was extracted using the Qiagen DNeasy Blood \& Tissue Kit (Qiagen, Hilden, Germany) as previously described [4].

\subsection{PCRs of Rickettsial Genes}

The following genes were investigated for the molecular characterization of the unknown SFG sp.: citrate synthase $(g l t A)$, outer membrane protein A $(o m p A)$ and B (ompB), cell surface antigen 4 (sca4 or geneD), 17-kDa outer membrane antigen ( $h$ trA $A), 16 \mathrm{~S}$ rDNA and the 23S-5S IGS. Table 1 gives an overview of the primers used.

The PCRs were performed with the Phire Hot Start II polymerase kit (Thermo Fisher Scientific, Vienna, Austria) using $5 \mu \mathrm{L}$ Phire reaction buffer, $400 \mathrm{nM}$ dNTPs each (Solis Biodyne, Tartu, Estonia), $400 \mathrm{nM}$ of each primer, $0.5 \mu \mathrm{L}$ Phire II polymerase and $2.5 \mu \mathrm{L}$ template DNA (1:5 diluted) and PCR-grade H2O (Sigma-Aldrich, Darmstadt, Germany) in a total volume of $25 \mu \mathrm{L}$. In the case of unsuccessful PCR of certain fragments, the mastermix was adjusted by using $200 \mathrm{nM}$ dNTPs each and $0.125 \mu \mathrm{L}$ Phire II polymerase that improved some PCRs. All PCRs were run in a Biorad Touch C-1000 thermal cycler (Hercules, CA, USA) using the following protocol: an initial denaturation step of $98^{\circ} \mathrm{C}$ for $30 \mathrm{~s}$, followed by 45 cycles of $98^{\circ} \mathrm{C}$ for $5 \mathrm{~s}$, respective annealing temperature $(\mathrm{Ta}){ }^{\circ} \mathrm{C}$ for $5 \mathrm{~s}$ and $72{ }^{\circ} \mathrm{C}$ for $15 \mathrm{~s}$ and, lastly, a final elongation step at $72{ }^{\circ} \mathrm{C}$ for $30 \mathrm{~s}$.

Amplification of the $g l t A$ gene was performed using two PCRs spanning a total of $1150 \mathrm{bp}$. The first fragment (I) with a product length of 398 base pairs (bp) was amplified at $50{ }^{\circ} \mathrm{C} \mathrm{Ta}$, the second fragment (II) of $777 \mathrm{bp}$ was run at $55^{\circ} \mathrm{C}$ Ta.

The ompA gene sequences were obtained by using five different PCRs; fragment I was the amplicon of the first part of the gene. The following tandem repeat region was not covered by the PCRs. Fragments II to V were assembled into a 3221 bp long consensus sequence. Fragment I (632 bp) was run at $55^{\circ} \mathrm{C} \mathrm{Ta}$, fragment II (819 bp), IV (889 bp) and V (892 bp) at $50{ }^{\circ} \mathrm{C}$ Ta and fragment III (901 bp) at $46^{\circ} \mathrm{C}$ Ta.

The $о т p B$ gene sequence resulted from seven PCRs, all of which were run with a Ta of $50{ }^{\circ} \mathrm{C}$. The product lengths were 856, 881, 1022, 876, 812, 885 and 648 bp, for fragments I to VII, respectively, resulting in a 4934 bp spanning region upon assembling. 
Table 1. Primers used for characterization of the novel Rickettsia sp.

\begin{tabular}{|c|c|c|c|c|}
\hline Gene & Fragment & Primer Name & Primer Sequence $\left(5^{\prime} \rightarrow 3^{\prime}\right)$ & Reference \\
\hline \multirow[t]{4}{*}{ gltA } & \multirow[t]{2}{*}{$I^{1}$} & CS-78 & GCAAGTATCGGTGAGGATGTAAT & \multirow[t]{4}{*}{ [7] } \\
\hline & & CS-323 & GCTTCCTTAAAATTCAATAAATCAGGAT & \\
\hline & \multirow[t]{2}{*}{$\mathrm{II}^{1}$} & CS-239 & GCTCTTCTCATCCTATGGCTATTAT & \\
\hline & & CS-1069 & CAGGGTCTTCGTGCATTTCTT & \\
\hline \multirow[t]{10}{*}{ ompA } & \multirow[t]{2}{*}{$\mathrm{I}^{1}$} & $190-70$ & ATGGCGAATATTTCTCCAAAA & \multirow[t]{10}{*}[8]{} \\
\hline & & $190-701$ & GTTCCGTTAATGGCAGCATCT & \\
\hline & \multirow[t]{2}{*}{$\mathrm{II}^{1}$} & $190-3588$ & AACAGTGAATGTAGGAGCAG & \\
\hline & & $190-4406$ & ACTATACCCTCATCGTCATT & \\
\hline & \multirow[t]{2}{*}{ III } & $190-4338$ & TTCAGGAAACGACCGTACG & \\
\hline & & $190-5238$ & ACTATTAAAGGCTAGGCTATT & \\
\hline & \multirow{2}{*}{ IV } & $190-5125$ & GCGGTTACTTTAGCCAAAGG & \\
\hline & & $190-6013$ & TCTTCTGCGTTGCATTACCG & \\
\hline & \multirow[t]{2}{*}{$\mathrm{V}^{1}$} & $190-5917$ & TCAGGGAATAAAGGTCCTG & \\
\hline & & $190-6808$ & CACGAACTTTCACACTACC & \\
\hline \multirow[t]{14}{*}{ отрB $B$} & \multirow[t]{2}{*}{$\mathrm{I}^{1}$} & M59 F & CCGCAGGGTTGGTAACTGC & \multirow[t]{14}{*}{ [9] } \\
\hline & & $120-807 \mathrm{R}$ & CCTTTTAGATTACCGCCTAA & \\
\hline & \multirow[t]{2}{*}{ II } & $120-607 \mathrm{~F}$ & AATATCGGTGACGGTCAAGG & \\
\hline & & $120-1497$ & CCTATATCGCCGGTAATT & \\
\hline & \multirow[t]{2}{*}{ III } & $120-1378$ & CCTATATCGCCGGTAATT & \\
\hline & & $120-2399$ & CTTGTTTGTTTAATGTTACGGT & \\
\hline & \multirow[t]{2}{*}{ IV } & $120-2113$ & CGATGCTAACGTAGGTTCTT & \\
\hline & & $120-2988$ & CCGGCTATACCGCCTGTAGT & \\
\hline & \multirow[t]{2}{*}{$\mathrm{V}$} & $120-2788$ & AAACAATAATCAAGGTACTGT & \\
\hline & & $120-3599$ & TACTTCCGGTTACAGCAAAGT & \\
\hline & \multirow[t]{2}{*}{ VI } & $120-3462$ & CCACAGGAACTACAACCATT & \\
\hline & & $120-4346$ & CGAAGAAGTAACGCTGACTT & \\
\hline & \multirow[t]{2}{*}{ VII $^{1}$} & $120-4232$ & GGTTTCTCATTCTCTCTATATGG & \\
\hline & & $120-4879$ & TTAGAAGTTTACACGGACTTTT & \\
\hline \multirow[t]{10}{*}{ sca4 } & \multirow[t]{2}{*}{$\mathrm{I}^{1}$} & D1f & ATGAGTAAAGACGGTAACCT & \multirow[t]{10}{*}[10]{} \\
\hline & & D928r & AAGCTATTGCGTCATCTCCG & \\
\hline & \multirow[t]{2}{*}{ II } & D767f & CGATGGTAGCATTAAAAGCT & \\
\hline & & D1390r & CTTGCTTTTCAGCAATATCAC & \\
\hline & III & D1219f & ССАААТСТТСТTAАТАCAGC & \\
\hline & & D1876r & TAGTTTGTTCTGCCATAATC & \\
\hline & IV & D1738f & GTATCTGAATTAAGCAATGCG & \\
\hline & & D2482r & CTATAACAGGATTAACAGCG & \\
\hline & $\mathrm{V}^{1}$ & $\mathrm{D} 2338 \mathrm{f}$ & GATGCAGCGAGTGAGGCAGC & \\
\hline & & D3069r & TCAGCGTTGTGGAGGGGAAG & \\
\hline htrA & $\mathrm{I}^{1}$ & $17 \mathrm{k}-5$ & GCTTTACAAAATTCTAAAAACCATATA & [7] \\
\hline & & $17 \mathrm{k}-3$ & TGTCTATCAATTCACAACTTGCC & \\
\hline $16 \mathrm{~S}$ rDNA & I & $\mathrm{fD} 1$ & AGAGTTTGATCCTGGCTCAG & {$[11]$} \\
\hline & & rP1 & ACGGTTACCTTGTTACGACTT & \\
\hline $\begin{array}{l}23 S-5 S \\
\text { ICS }\end{array}$ & $I^{1}$ & $\mathrm{RCK} / 23-5-\mathrm{F}$ & GATAGGTCRGRTGTGGAAGCAC & [12] \\
\hline & & $\mathrm{RCK} / 23-5-\mathrm{R}$ & TCGGGAYGGGATCGTGTGTTTC & \\
\hline
\end{tabular}

${ }^{1}$ The fragments were cloned to obtain longer gene sequences.

Amplification of sca4 (gene D) consisted of five PCRs performed at $50{ }^{\circ} \mathrm{C}$ Ta. The fragment sizes were $910,624,661,745$ and $738 \mathrm{bp}$, for fragments I to V, respectively. Together they spanned a region of 3078 bp of the gene.

The PCR of the $17 \mathrm{kDa}$ antigen $(h t r A)$ was run at $55{ }^{\circ} \mathrm{C} \mathrm{Ta}$, resulting in a $549 \mathrm{bp}$ long fragment covering the whole gene.

The amplification of the $16 \mathrm{~S}$ rDNA was performed with the following protocol: $98{ }^{\circ} \mathrm{C}$ for $30 \mathrm{~s}$ followed by 45 cycles at $98{ }^{\circ} \mathrm{C}$ for $10 \mathrm{~s}, 58^{\circ} \mathrm{C}$ for $10 \mathrm{~s}, 72{ }^{\circ} \mathrm{C}$ for $20 \mathrm{~s}$ and a final elongation for $30 \mathrm{~s}$ at $72{ }^{\circ} \mathrm{C}$. The obtained PCR product was $1462 \mathrm{bp}$ long.

Finally, the 23S-5S IGS PCR was run with a touchdown program, as described previously [4]. Depending on the species, the product length of this target varied between 341 and $413 \mathrm{bp}$ (http: //insilico.ehu.eus/PCR/). 


\subsection{PCR Purification and Sequencing}

The entire PCR reaction volume was loaded onto a $1 \%$ agarose gel containing GelRed (Biotrend, Cologne, Germany). The bands were excised and purified using the QIAquick Gel Extraction kit (Qiagen, Hilden, Germany). The purified amplicons were sent to Microsynth (Microsynth Austria $\mathrm{GmbH}$, Vienna, Austria) for bidirectional sequencing.

Certain PCR products were cloned into a plasmid for sequencing in order to gather full-length sequences of the gene endings. To this end, the purified fragments were ligated into the pJET1.2 blunt end cloning vector and cloning was performed with the CloneJET PCR cloning kit (Thermo Fisher Scientific, Vienna, Austria) using DH $5 \alpha$ cells according to the manufacturer's instructions. The plasmids were extracted using the GeneJet Plasmid Miniprep kit (Thermo Fisher Scientific, Vienna, Austria) and sent in for sequencing (Microsynth Austria GmbH, Vienna, Austria).

The obtained sequenced fragments were assembled and analyzed using MEGA7 [13].

\subsection{Data Availability}

The sequences obtained during this study were submitted to GenBank and are available under the following accession numbers: MT424977-MT424983.

\section{Results}

We performed the phylogenetic analyses in MEGA7 [13] singularly for each gene using reference sequences of strains, for which whole-genome sequence data were available. Additionally, other strains (e.g., Candidatus Rickettsia spp. or species for which complete genome data were not yet available) were also included in the single-gene analyses in the case that the available sequences were long enough.

In the single-gene analyses, all phylogenetic trees were constructed using the neighbor-joining algorithm with the Kimura 2-parameter method and a discrete Gamma distribution inferred from 1000 bootstrap replicates. Trees were drawn to scale with branch lengths indicating the evolutionary distance. Gaps and missing data were deleted. The accession numbers and strain designations of the genospecies included in the different analyses are displayed in the phylogenetic trees.

\subsection{Phylogenetic Analysis of the gltA Gene}

After cloning and assembling the two PCR fragments of gltA in MEGA7, a total consensus sequence of $1150 \mathrm{bp}$ was obtained covering glt $A$ gene positions 82 to 1231, when compared to reference strains of the SFG. An initial DNA comparison using the Basic Local Alignment Search Tool (BLAST) showed $99.57 \%$ similarity to R. parkeri strain Atlantic Rainforest (CP040325.1) as well as similarity to some R. sibirica strains (e.g., KU310587.1).

In order to construct a phylogenetic tree of the gltA gene (Figure 1a), a total amount of 1051 nucleotide positions were included comprising 36 different Rickettsia strains. The tree covered gene positions 105 to 1155 for SFG Rickettsia spp. (or, in the case of R. belli, 105 to 1158). 


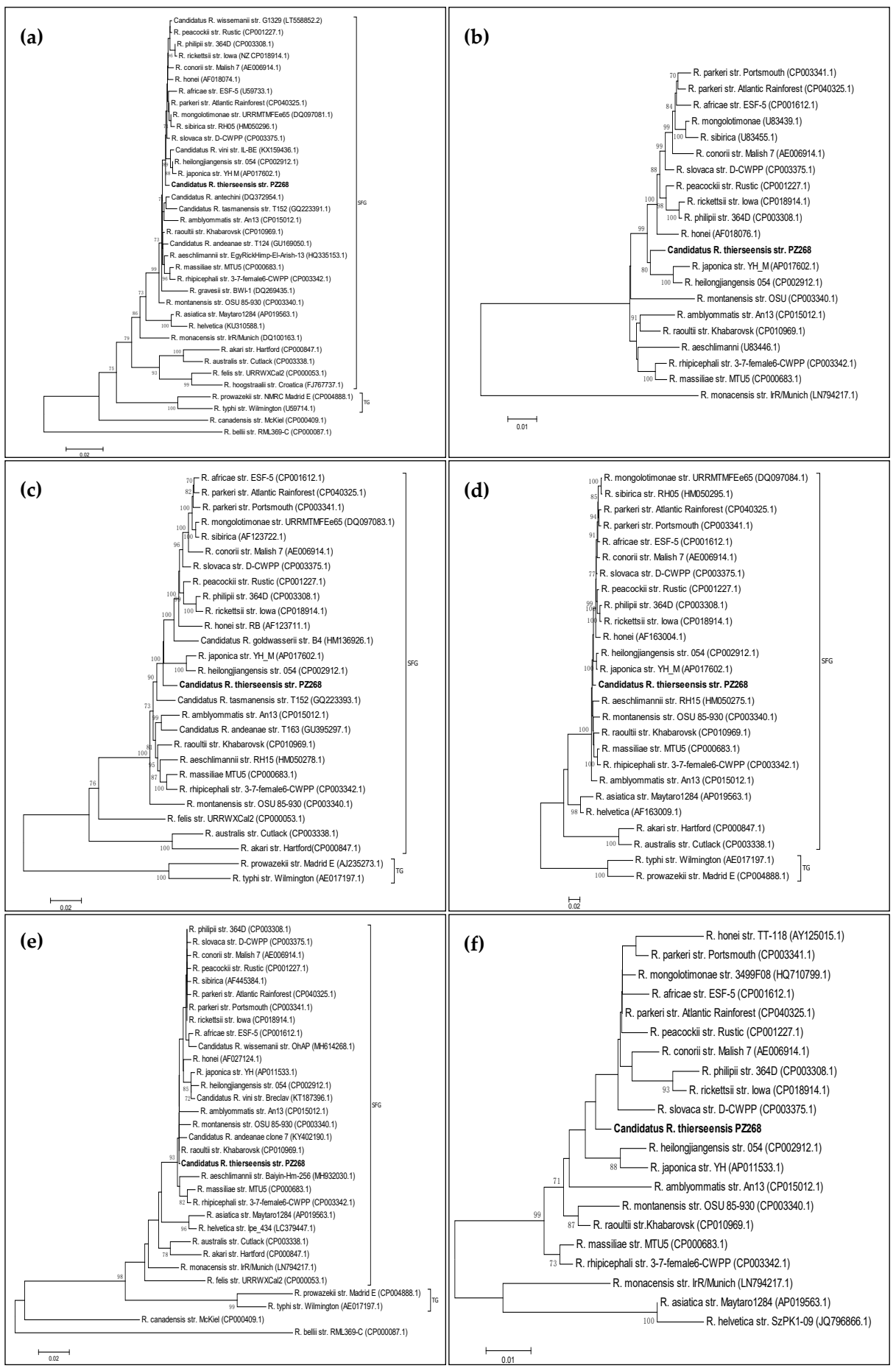

Figure 1. Phylogenetic trees for single genes. Neighbor-joining trees constructed with the Kimura 2-parameter method and inferred from 1000 bootstrap replicates. Only bootstrap values $\geq 70 \%$ are shown. The trees were drawn to scale with branch lengths indicating evolutionary distances. Gaps and missing data were deleted. Our strain under study is displayed in bold letters. (a) gltA gene showing 36 Rickettsia strains using a total of 1051 positions in the final dataset; (b) ompA gene including 21 strains and 3144 positions; (c) ompB gene including 28 strains and 4739 positions; (d) sca4 gene displaying 26 strains and constructed from 2010 positions; (e) htrA gene showing 32 strains using 413 positions; (f) 23S-5S intergenic spacer region for 21 strains and built from 345 positions in the final dataset. 


\subsection{Phylogenetic Analysis of the ompA Gene}

Concerning the ompA gene, we performed the analysis in two steps as we did not want to include the tandem repeat separating the gene segments of interest in the analysis. The first segment (fragment I) comprised a sequence of $632 \mathrm{bp}$. A BLAST search of this fragment resulted in $96.20 \%$ identity to $R$. raoultii isolate Alear06 (KX506738.1). The second segment was obtained by assembling fragments II to V of the ompA PCRs, resulting in a $3221 \mathrm{bp}$ long consensus sequence. The BLAST comparison showed $98.45 \%$ identity to various $R$. heilongjiangensis strains (e.g., AP019865.1) as well as to some R. slovaca strains (e.g., CP003375.1).

The ompA gene is not available for all Rickettsia spp., especially not for most non-SFG Rickettsia spp. (e.g., R. belli, R. typhi, R. prowazekii). Therefore, they are not shown in the ompA tree. This also applies to $R$. helvetica and R. asiatica for which the ompA sequence is also not available even though they belong to the SFG. For fragment I, it was possible to include some transitional group Rickettsia spp., i.e., R. akari, R. australis and R. canadensis. However, for the longer fragment (II to V), these species also had to be excluded for an adequate alignment. The tree constructed for the longer fragment of the omp A gene containing 3144 nucleotide positions is shown in Figure $1 \mathrm{~b}$.

\subsection{Phylogenetic Analysis of the ompB Gene}

After assembling the seven sequenced fragments of the $о т p B$ gene, we obtained a 4934 bp long spanning sequence, which displayed $97.34 \%$ identity to R. slovaca (CP003375.1 and CP002528.1). For the phylogenetic tree (Figure 1c), R. belli and R. canadensis had to be excluded to achieve an adequate alignment for analysis. Moreover, the SFG species R. asiatica, $R$. monacensis and $R$. helvetica were also excluded to construct the tree from a longer gene region spanning 4739 nucleotides.

\subsection{Phylogenetic Analysis of the sca4 Gene (Gene D)}

Upon assembling, the five PCR products of the sca4 gene yielded a nucleotide sequence of 3078 bp. Just like for the ompB gene, the closest similarity was obtained for $R$. slovaca with $98.48 \%$ identity (CP003375.1 and CP002428.1). To construct the tree, R. belli, R. felis, R. canadensis and R. monacensis were excluded. The phylogenetic tree built from 2010 positions is shown in Figure $1 \mathrm{~d}$.

\subsection{Phylogenetic Analysis of the htrA Gene (17-kDa Antigen)}

Amplification and cloning of the product of the $h t r A$ gene yielded a $547 \mathrm{bp}$ long sequence that displayed the closest similarity (99.63\% identity) to R. rickettsii (e.g., CP018914.1) and R. philipii (CP003308.1). The entire gene sequence of $h t r A$ comprising 480 nucleotides is contained within this assembly. When using the gene sequence without the flanking regions for database comparison, we found the closest similarity ( $99.79 \%$ identity) to R. raoultii strains (e.g., CP019435.1). The phylogenetic tree consisting of 32 sequences and covering gene positions 51 to 463 (413 nucleotide positions) is shown in Figure 1e.

\subsection{Phylogenetic Analysis of the $16 S$ rRNA Gene}

The 1094 bp long consensus sequence obtained from the 16S rRNA gene yielded 100\% identity to multiple Rickettsia strains belonging to the species $R$. raoultii (e.g., MK304546.1), R. conorii (e.g., MF002584.1) and R. gravesii (NR_157982.1). It is known that the 16S rRNA is not a valuable target for discriminating Rickettsia spp. and that many distinct species show $100 \%$ similarity to each other when comparing fragments of this gene. Therefore, due to low significance, we do not show a phylogenetic tree for this gene.

\subsection{Phylogenetic Analysis of the 23S-5S Intergenic Spacer (IGS)}

We cloned and sequenced a $386 \mathrm{bp}$ fragment of the 23S-5S IGS region and found the closest match (99.22\% identity) to R. parkeri strain Atlantic Rainforest (CP040325.1). To enable enclosure of more 
positions (in total 345) in the analysis, we only used SFG Rickettsia spp. to draw the phylogenetic tree (Figure 1f).

\subsection{Multigenic Analysis of the Concatenated Sequences}

To carry out a powerful multigene phylogenetic analysis, we selected 16 Rickettsia species and concatenated their $g l t A, o m p A, o m p B, s c a 4$ and $h t r A$ sequences. As a reference, we used $R$. africae strain ESF-5 (CP001612.1). Gaps and missing data were deleted, resulting in a different numbering of included nucleotides compared to the total spanning region. The glt $A$ sequence covered gene positions 82 to 1231 with 1150 nucleotides included, the ompA sequence covered positions 1 to 587 with 574 nucleotides included, the $\operatorname{omp} B$ sequence covered positions 38 to 4965 with 4880 nucleotides included, the sca4 sequence covered positions 1 to 3075 with 2840 nucleotides included and, finally, the $h t r A$ sequence covered gene positions 1 to 476 with all nucleotides included. Using these sequences, we constructed a maximum likelihood tree from 100 bootstrap replicates using the Tamura three-parameter model. To model evolutionary rate differences among sites, we applied a discrete Gamma distribution $(+\mathrm{G}$, parameter $=0.5282)$. Finally, we constructed the tree from 9920 total nucleotide positions retrieved from the five rickettsial genes and the 17 different Rickettsia spp. including our Candidatus Rickettsia thierseensis sp. (Figure 2). The branch lengths indicate the number of substitutions per site.

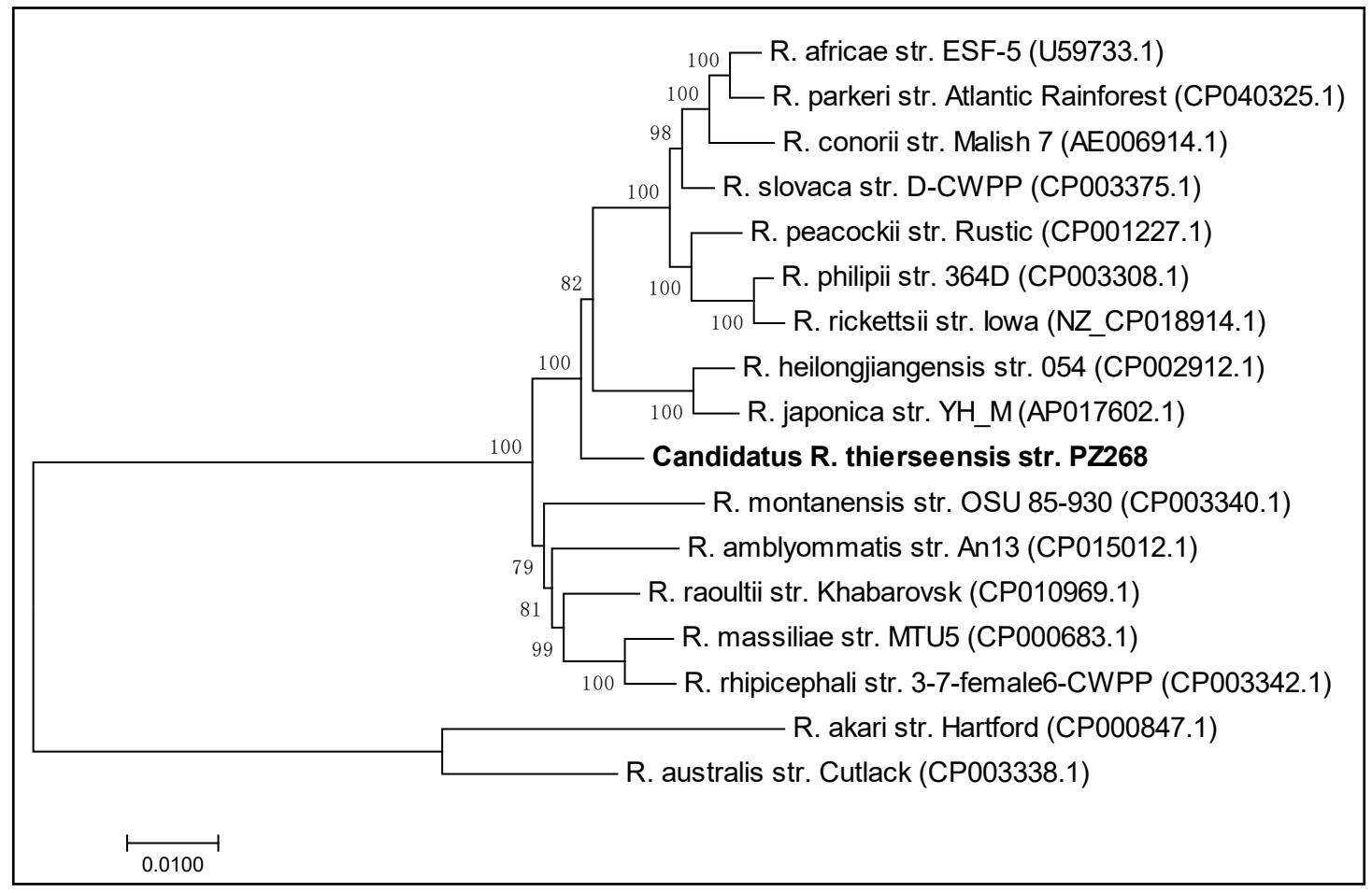

Figure 2. Maximum likelihood tree for multigenic phylogenetic analysis. Maximum likelihood tree built from 100 bootstrap replicates of the concatenated sequences of the gltA, ompA, ompB, sca4 and $h \operatorname{tr} A$ genes, respectively. The Tamura three-parameter model was applied using a discrete Gamma distribution. A total of 17 Rickettsia spp. were included and the final dataset contained 9920 positions. Our Candidatus Rickettsia thierseensis strain is indicated by bold letters.

\section{Discussion}

We describe a new Rickettsia species of the SFG that we identified in an I. ricinus nymph, which bit a patient in Thiersee, a village in the Austrian province of Tyrol. We do not know during which stage of the tick's life cycle this Rickettsia sp. was taken up or whether it was present within the tick as an endosymbiont and passed on transovarially. By negative serological testing of a paired sample, 
we at least ruled out the possibility that the tick had obtained this Rickettsia sp. from the human it was attached to. Moreover, the patient did not suffer from any symptoms evocative of rickettsiosis.

In our analysis, we clearly were able to allocate this new species to the SFG rickettsiae. There are several subgroups within the SFG, which are currently based around the species $R$. tamurae, R. massiliae, $R$. japonica and $R$. rickettsii [1]. In our multigenic analysis, our isolate branched between the $R$. japonica and R. massiliae groups. To characterize the novel Rickettsia sp., our aim was to cover the investigated genes as well as possible by using conventional molecular methods in an attempt to obtain long DNA sequences for analysis and facilitate submission to the GenBank database. Therefore, our data can easily be included in future phylogenetic comparisons of common rickettsial genes.

The discovery of new and emerging tick-borne microorganisms has a considerable impact on future research into tick-borne diseases. A large number of tick-borne microorganisms were initially discovered in their tick host before infection in humans or animals was proven. For example, this was the case with Candidatus Neoehrlichia mikurensis, which represented the first case of neoehrlichiosis in an immunocompromised patient in 2009 [14], approximately 10 years after its discovery as an Ehrlichia-like organism in I. ricinus ticks in the Netherlands [15]. Borrelia miyamotoi was also first identified in a tick from Japan in 1995 [16] before being associated with human illness for the first time 17 years later [17].

Although Rickettsia spp. are among the oldest known zoonotic agents, the situation is similar [18]. Currently, the SFG Rickettsia spp. found in ticks from Austria comprise R. helvetica, R. raoultii, R. monacensis and R. slovaca [4]. The first detection of R. helvetica in humans was reported in 1999 [19], although it was already isolated from ticks in 1979 [20]. R. raoultii and its genetic variants have been known since 1999, yet it was discovered in the scalp of a patient with tick-borne lymphadenitis (TIBOLA) as late as 2002 [21]. R. monacensis was initially isolated and described in 2002 from ticks from Germany [22], and the first human case occurred in 2007 in Spain [23]. Finally, R. slovaca, which was first identified in 1968, was detected by molecular methods in a patient in 1996 [24]. These examples underscore the importance of studying, discovering and appropriately describing new tick-borne microorganisms, even though the pathogenic potential is not yet known. With respect to Rickettsia spp., the genus has undergone rapid expansion in the past few years, leading to a large number of newly described species of unknown pathogenicity. However, due to its intracellular lifestyle, cultivation of Rickettsia spp. is laborious and not easily possible, making it difficult to obtain cultured isolates. Therefore, new (Candidatus) Rickettsia spp. are mainly discovered via molecular methods, resulting in a high number of new strains and putative species that are not yet available in culture and, hence, leading to Candidatus status.

In accordance with the current criteria for defining a new species in the Rickettsia genus, a nucleotide sequence similarity of less than $99.9 \%, 99.3 \%, 98.8 \%$ and $99.2 \%$ to the glt $A, s c a 4$, ompA and ompB genes, respectively, is required [5]. Our isolate shows a similarity of $99.6 \%, 98.5 \%, 98.5 \%$ and $97.3 \%$ to the $g l t A, s c a 4, o m p A$ and $о m p B$ genes, respectively, of known and validated species. Thus, the fulfillment of these selection criteria proves the presence of a new SFG Rickettsia species for which we propose the name Candidatus Rickettsia thierseensis.

Author Contributions: Conceptualization, A.-M.S. and M.W.; methodology, A.-M.S.; validation, A.-M.S.; formal analysis, A.-M.S.; investigation, A.-M.S.; resources, D.H., G.S., M.M.; data curation, A.-M.S.; writing —original draft preparation, A.-M.S.; writing—review and editing, A.-M.S., M.W., D.H., G.S., H.S., M.M.; visualization, A.-M.S., M.W.; supervision, G.S., H.S., M.M.; project administration, A.-M.S.; funding acquisition, G.S., H.S. All authors have read and agreed to the published version of the manuscript.

Funding: This research received no external funding.

Conflicts of Interest: The authors declare no conflict of interest. 


\section{References}

1. Diop, A.; El Karkouri, K.; Raoult, D.; Fournier, P.-E. Genome sequence-based criteria for demarcation and definition of species in the genus Rickettsia. Int. J. Syst. Evol. Microbiol. 2020, 70, 1738-1750. [CrossRef] [PubMed]

2. Shpynov, S.N.; Fournier, P.E.; Pozdnichenko, N.N.; Gumenuk, A.S.; Skiba, A.A. New approaches in the systematics of rickettsiae. New Microbes New Infect. 2018, 23, 93-102. [CrossRef] [PubMed]

3. Parola, P.; Paddock, C.D.; Raoult, D. Tick-borne rickettsioses around the world: Emerging diseases challenging old concepts. Clin. Microbiol. Rev. 2005, 18, 719-756. [CrossRef]

4. Schötta, A.M.; Wijnveld, M.; Stockinger, H.; Stanek, G. Approaches for reverse line blot-based detection of microbial pathogens in Ixodes ricinus ticks collected in Austria and impact of the chosen method. Appl. Environ. Microbiol. 2017, 83, 1-18. [CrossRef] [PubMed]

5. Fournier, P.E.; Dumler, J.S.; Greub, G.; Zhang, J.; Wu, Y.; Raoult, D. Gene sequence-based criteria for identification of new Rickettsia isolates and description of Rickettsia heilongjiangensis sp. nov. J Clin Microbiol 2003, 41, 5456-5465. [CrossRef] [PubMed]

6. Black, W.C., 4th; Piesman, J. Phylogeny of hard- and soft-tick taxa (Acari: Ixodida) based on mitochondrial 16S rDNA sequences. Proc. Natl. Acad. Sci. USA 1994, 91, 10034-10038. [CrossRef]

7. Labruna, M.B.; McBride, J.W.; Bouyer, D.H.; Camargo, L.M.A.; Camargo, E.P.; Walker, D.H. Molecular evidence for a spotted fever group Rickettsia species in the tick Amblyomma longirostre in Brazil. J. Med. Entomol. 2004, 41, 533-537. [CrossRef]

8. Fournier, P.E.; Roux, V.; Raoult, D. Phylogenetic analysis of spotted fever group rickettsiae by study of the outer surface protein rOmpA. Int. J. Syst. Bacteriol. 1998, 48 Pt 3, 839-849. [CrossRef]

9. Roux, V.; Raoult, D. Phylogenetic analysis of members of the genus Rickettsia using the gene encoding the outer-membrane protein rOmpB (ompB). Int. J. Syst. Evol. Microbiol. 2000, 50, 1449-1455. [CrossRef]

10. Sekeyova, Z.; Roux, V.; Raoult, D. Phylogeny of Rickettsia spp. inferred by comparing sequences of "gene D", which encodes an intracytoplasmic protein. Int. J. Syst. Evol. Microbiol. 2001, 51, 1353-1360. [CrossRef]

11. Weisburg, W.G.; Barns, S.M.; Pelletie, D.A.; Lane, D.J.; Pelletier, D.A.; Lane, D.J. 16S ribosomal DNA amplification for phylogenetic study. J. Bacteriol. 1991, 173, 697-703. [CrossRef]

12. Jado, I.; Escudero, R.; Gil, H.; Jimenez-Alonso, M.I.; Sousa, R.; Garcia-Perez, A.L.; Rodriguez-Vargas, M.; Lobo, B.; Anda, P. Molecular method for identification of Rickettsia species in clinical and environmental samples. J. Clin. Microbiol. 2006, 44, 4572-4576. [CrossRef] [PubMed]

13. Kumar, S.; Stecher, G.; Tamura, K. MEGA7: Molecular Evolutionary Genetics Analysis Version 7.0 for Bigger Datasets. Mol. Biol. Evol. 2016, 33, 1870-1874. [CrossRef]

14. Welinder-Olsson, C.; Kjellin, E.; Vaht, K.; Jacobsson, S.; Wennerås, C. First case of human “Candidatus neoehrlichia mikurensis" infection in a febrile patient with chronic lymphocytic leukemia. J. Clin. Microbiol. 2010, 48, 1956-1959. [CrossRef]

15. Schouls, L.M.; Van de Pol, I.; Rijpkema, S.G.T.; Schot, C.S. Detection and Identification of Ehrlichia, Borrelia burgdorferi Sensu Lato, and Bartonella Species in Dutch Ixodes ricinus Ticks. J. Clin. Microbiol. 1999, 37, 2215-2222. [CrossRef]

16. Fukunaga, M.; Takahashi, Y.; Tsuruta, Y.; Matsushita, O.; Ralph, D.; McClelland, M.; Nakao, M. Genetic and phenotypic analysis of Borrelia miyamotoi sp. nov., isolated from the ixodid tick Ixodes persulcatus, the vector for Lyme disease in Japan. Int. J. Syst. Bacteriol. 1995, 45, 804-810. [CrossRef] [PubMed]

17. Gugliotta, J.L.; Goethert, H.K.; Berardi, V.P.; Telford, S.R., III. Meningoencephalitis from Borrelia miyamotoi in an Immunocompromised Patient. N. Engl. J. Med. 2013, 368, 240-245. [CrossRef]

18. Parola, P.; Paddock, C.D.; Socolovschi, C.; Labruna, M.B.; Mediannikov, O.; Kernif, T.; Abdad, M.Y.; Stenos, J.; Bitam, I.; Fournier, P.-E.; et al. Update on tick-borne rickettsioses around the world: A geographic approach. Clin. Microbiol. Rev. 2013, 26, 657-702. [CrossRef]

19. Nilsson, K.; Lindquist, O.; Påhlson, C. Association of Rickettsia helvetica with chronic perimyocarditis in sudden cardiac death. Lancet 1999, 354, 1169-1173. [CrossRef]

20. Beati, L.; Peter, O.; Burgdorfer, W.; Aeschlimann, A.; Raoult, D. Confirmation that Rickettsia helvetica sp. nov. is a distinct species of the spotted fever group of rickettsiae. Int. J. Syst. Bacteriol. 1993, 43, 521-526. [CrossRef]

21. Mediannikov, O.; Matsumoto, K.; Samoylenko, I.; Drancourt, M.; Roux, V.; Rydkina, E.; Davoust, B.; Tarasevich, I.; Brouqui, P.; Fournier, P.E. Rickettsia raoultii sp. nov., a spotted fever group rickettsia 
associated with Dermacentor ticks in Europe and Russia. Int. J. Syst. Evol. Microbiol. 2008, 58, 1635-1639. [CrossRef] [PubMed]

22. Simser, J.A.; Palmer, A.T.; Fingerle, V.; Wilske, B.; Kurtti, T.J.; Munderloh, U.G. Rickettsia monacensis sp. nov., a spotted fever group rickettsia, from ticks (Ixodes ricinus) collected in a European city park. Appl. Environ. Microbiol. 2002, 68, 4559-4566. [CrossRef] [PubMed]

23. Jado,I.; Oteo,J.A.; Aldámiz,M.; Gil,H.; Escudero, R.; Ibarra, V.; Portu,J.; Portillo, A.; Lezaun, M.J.; García-Amil, C.; et al. Rickettsia monacensis and human disease, Spain. Emerg. Infect. Dis. 2007, 13, 1405-1407. [CrossRef]

24. Raoult, D.; Berbis, P.; Roux, V.; Xu, W.; Maurin, M. A new tick-transmitted disease due to Rickettsia slovaca. Lancet 1997, 350, 112-113. [CrossRef]

Publisher's Note: MDPI stays neutral with regard to jurisdictional claims in published maps and institutional affiliations.

(C) 2020 by the authors. Licensee MDPI, Basel, Switzerland. This article is an open access article distributed under the terms and conditions of the Creative Commons Attribution (CC BY) license (http://creativecommons.org/licenses/by/4.0/). 